\title{
Research
}

\section{Antibiotic use and serious complications following acute otitis media and acute sinusitis:}

\author{
a retrospective cohort study
}

\begin{abstract}
Background

Most people with acute otitis media (AOM) and acute sinusitis (AS) do not benefit from antibiotics, and GPs are under increasing pressure to reduce antibiotic prescribing. Concern about the risk of complications can drive unnecessary prescribing.

Aim

To describe the incidence of serious complications following AOM and AS, and to determine whether antibiotics are protective.

\section{Design and setting}

This was a retrospective cohort study using the Clinical Practice Research Datalink database to identify patients diagnosed in general practice with AOM or AS between 1 January 1982 and 31 December 2012.
\end{abstract}

\section{Method}

The incidence of brain abscess and acute mastoiditis following $\mathrm{AOM}$, and of brain abscess and orbital cellulitis following AS, were calculated. as was the association between antibiotics and the development of these complications and numbers needed to treat (NNT).

\section{Results}

The incidence of brain abscess and acute mastoiditis following AOM were 0.03 (95\% confidence interval $[\mathrm{Cl}]=0.01$ to 0.20 ) and $5.62(95 \% \mathrm{Cl}=4.81$ to 6.56$)$ per 10000 AOM episodes, respectively. The incidence of brain abscess and orbital cellulitis following AS was $0.11(95 \% \mathrm{Cl}=0.05$ to 0.26$)$ and 1.50 (95\% $\mathrm{Cl}=1.17$ to 1.90 ) per $10000 \mathrm{AS}$ episodes, respectively. Antibiotic prescription for AOM was associated with lower odds of developing acute mastoiditis lodds ratio [OR] 0.54; $95 \% \mathrm{Cl}=0.37$ to 0.79 ); NNT to prevent one case was 2181 (95\% $\mathrm{Cl}=1196$ to 5709). Antibiotic prescribing for AS was associated with lower odds of subsequent brain abscess (OR 0.12; $95 \%$ $\mathrm{Cl}=0.02$ to 0.70 ): NNT to prevent one case was 19988 (95\% Cl = 4951 to 167 099). No significant association between antibiotic prescription and development of orbital cellulitis following AS were found (OR $0.56 ; 95 \% \mathrm{Cl}=0.27$ to 1.12 ).

\section{Conclusion}

Serious complications following AOM and AS are rare. Antibiotics are associated with lower odds of developing complications, but the NNT are large.

\section{Keywords}

acute otitis media; acute sinusitis; antibiotics; complications; general practice; retrospective studies.

\section{INTRODUCTION}

Given the current global threat from increasing antimicrobial resistance, judicious use of antibiotics is a major public health challenge. ${ }^{1,2}$ Over $80 \%$ of antibiotic prescribing in England occurs in general practice, ${ }^{3}$ and the National Institute for Health and Care Excellence (NICE) estimates that respiratory tract infections (RTIs) account for $60 \%$ of antibiotic prescribing. ${ }^{4}$

Despite antibiotic stewardship activities, antibiotics are prescribed for up to $80 \%$ of RTIs in primary care, ${ }^{5}$ with prescribing particularly high for acute otitis media (AOM) and acute sinusitis (AS). ${ }^{5-7}$ Experts have suggested that many antibiotic prescriptions are unnecessary and that 'ideal' levels of prescribing for RTIs should be much lower.?

AOM is one of the commonest childhood infections, ${ }^{8}$ and $\mathrm{AS}$ is one of the commonest conditions diagnosed in primary care. ${ }^{9}$ Most episodes of AOM and AS resolve without antibiotics, and antibiotics offer little benefit in terms of symptom resolution. ${ }^{8-14}$ NICE currently recommends that most cases of $\mathrm{AOM}$ and $\mathrm{AS}$ be managed without antibiotics or with a back-up antibiotic prescription. ${ }^{15,1}$ $\mathrm{AOM}$ and $\mathrm{AS}$ can be complicated by serious conditions, such as acute mastoiditis and orbital cellulitis respectively, and both are predisposing factors for brain abscess. ${ }^{17}$

The incidence of mastoiditis following otitis media and protective effect of antibiotics has been examined in two previous UK

R Cushen, MPH, MRCGP, MFPH, GP, Cardiff and Vale University Health Board, University Hospital of Wales, Cardiff; consultant in public health medicine, Cwm Taf Morgannwg Public Health Team, Public Health Wales, Glanrhyd Hospital, Bridgend. NA Francis, PhD, PGD (Epidemiology) MRCGP, professor of primary care research, School of Primary Care, Population Sciences and Medical Education, Aldermoor Health Centre, Southampton.

Address for correspondence

Rebecca Cushen, Cwm Taf Morgannwg Public retrospective cohort studies. ${ }^{18,19}$ One of these studies only included children and both studies used a broad set of codes for otitis media, which is likely to have reduced their specificity in relation to the diagnosis of AOM. Risk of orbital abscess following sinusitis has been explored in a previous Swedish cohort study, ${ }^{20}$ but this study did not explore whether antibiotics modified this risk and, to the authors' knowledge, no other studies exploring the risk of these complications at an individual level have been identified.

Fear of serious complications can drive antibiotic prescribing in RTIs. ${ }^{21}$ Therefore, understanding the risk of septic complications following $\mathrm{AOM}$ or $\mathrm{AS}$, and whether antibiotics are protective, can help allay fears and may lead to more rational prescribing.

This study aimed to determine the incidence of acute mastoiditis and brain abscess following AOM, and of orbital cellulitis and brain abscess following AS, and to assess whether antibiotics are protective against the development of these complications.

\section{METHOD}

\section{Study design and population}

A retrospective cohort study was undertaken of patients diagnosed in primary care with AOM or AS and recorded in the Clinical Practice Research Datalink (CPRD) database. CPRD contains anonymised

Health Team, Public Health Wales, Glanrhyd Hospital, Bridgend CF31 4LN, UK.

Email: rebecca.cushendawales.nhs.uk

Submitted: 19 August 2019; Editor's response: 8 September 2019; final acceptance:

12 November 2019.

CBritish Journal of General Practice

This is the full-length article (published online 10 Mar 2020) of an abridged version published in print. Cite this version as: Br J Gen Pract 2020; DOI: https://doi.org/10.3399/bjgp20X708821 


\section{How this fits in}

Concern about reducing the risk of serious complications can drive antibiotic prescribing for common infections, such as acute otitis media (AOM) and acute sinusitis (AS), and use of antibiotics is the major driver of antibiotic resistance. The association between use of antibiotics for $\mathrm{AOM}$ and $\mathrm{AS}$, and the subsequent risk of acute mastoiditis, brain abscess, and orbital cellulitis, has not been adequately explored. This study demonstrates that these serious complications are extremely uncommon. Antibiotic use was associated with a lower risk of acute mastoiditis following AOM and brain abscess following AS, but for both conditions thousands of patients would need to be treated to prevent a single instance of one complication.

primary care records of approximately $7 \%$ of the UK population and its predecessor the General (G)PRD was identified as containing high-quality data. ${ }^{19,22}$

\section{Defining the population}

AOM and AS diagnoses between 1 January 1982 and 31 December 2012 in children (aged $<20$ years) and adults laged $\geq 20$ years) were identified using prespecified Read codes. Consultations were included if the diagnosis date occurred on or after the patients' data were defined as 'acceptable' by the CPRD. Consultations occurring within 14 days of initial AOM consultation and 28 days of initial AS consultation were defined as part of the same illness episode. Patients prescribed an antibiotic $\leq 14$ days before AOM/AS diagnosis were excluded. Patients with $>1$ illness episode were included in both $\mathrm{AOM}$ and AS cohorts.

\section{Antibiotic exposure}

Antibiotic exposure was defined as prescription of an antibiotic on the same date as initial AOM/AS diagnosis. Antibiotics were defined as all oral antibiotics listed in the British National Formulary 64 (chapter 5.1).23

\section{Outcome measures}

Outcomes were identified from primary care Read codes or $10^{\text {th }}$ Edition of the International Classification of Diseases/ Office of Population Censuses and Surveys Classification of Interventions and Procedures (version 4) codes identified from linked Hospital Episode Statistics (HES) data.

The outcomes defined were:

- brain abscess $\leq 90$ days following AOM/AS diagnosis;

- acute mastoiditis $\leq 90$ days following AOM diagnosis; and

- orbital cellulitis $\leq 90$ days following AS diagnosis.

\section{Incidence of complications}

The incidence of acute mastoiditis and brain abscess following AOM was calculated, as was the incidence of orbital cellulitis and brain abscess following AS. Additional stratified analyses were undertaken to calculate incidence of outcomes for those aged $\leq 20$ years and those aged $>20$ years. Ninety-five per cent confidence intervals (Cls) were calculated using the Wilson method. ${ }^{24}$

\section{Primary analysis}

The association between antibiotics and outcomes was assessed using logistic regression to calculate crude odds ratios (ORs). The association between potential confounders lage, smoking history, asplenia, HIV/AIDS, transplanted organ, cerebrospinal fluid shunt, diabetes mellitus, and severe chronic kidney disease) and antibiotic exposure, and the outcome of interest, were examined using logistic regression. Confounders significantly associated with both exposure and outcome $(P<0.05)$ were included in multivariable logistic regression models. Sequential logistic regression modelling was undertaken to identify the model that provided the best fit of the data and final crude/adjusted ORs were obtained.

Additional logistic regression analyses for acute mastoiditis following AOM and for orbital cellulitis/brain abscess following AS were undertaken in those aged $\leq 20$ years and $>20$ years.

\section{Numbers needed to treat}

For outcomes significantly associated with antibiotic prescription, the numbers needed to treat (NNT) (1/risk difference) and associated $95 \% \mathrm{Cl}$ were calculated using the Wilson method. ${ }^{24}$

Statistical analyses were undertaken using IBM SPSS Statistics (version 20.0).

\section{RESULTS}

The number of $\mathrm{AOM}$ and $\mathrm{AS}$ episodes identified was 286574 and 441873 , respectively (Figure 1 and 2). For patients 
Figure 1. CONSORT flow diagram for acute otitis media (AOM). CONSORT = Consolidated Standards of Reporting Trials. CPRD = Clinical Practice Research Datalink.

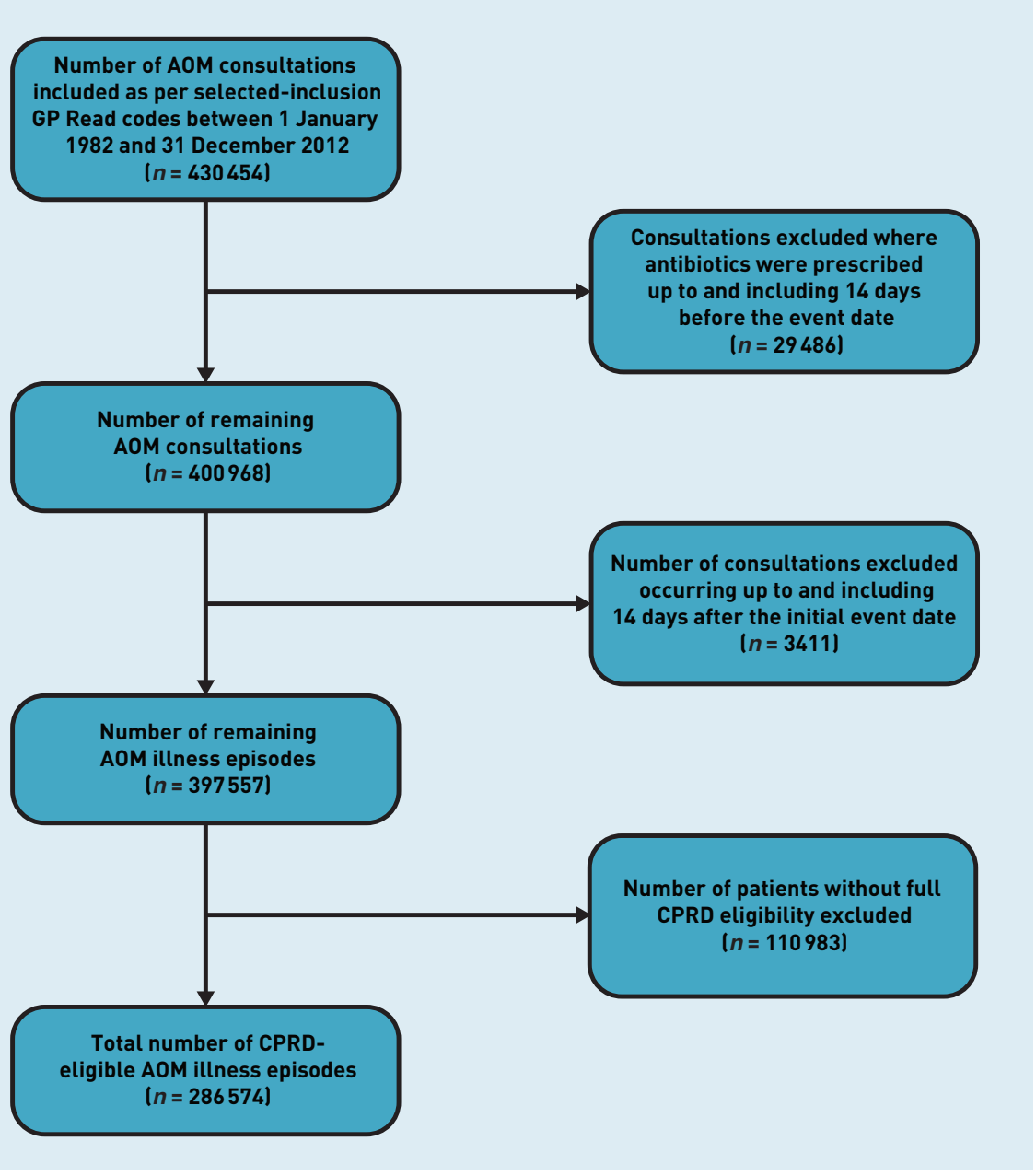

with $\mathrm{AOM}, \quad 86.9 \% \quad(n=249086)$ were prescribed antibiotics at initial consultation (Table 1), as were $92.1 \% \quad(n=407030)$ of patients with AS (Table 2). Baseline characteristics of both cohorts are shown in Table 1 and 2.

\section{Incidence of complications}

Incidence of brain abscess following AOM was 0.03 per 10000 AOM episodes $(95 \% \mathrm{Cl}=0.01$ to 0.20$)$. Incidence of acute mastoiditis following $\mathrm{AOM}$ was 5.62 per $10000 \mathrm{AOM}$ episodes $195 \% \mathrm{Cl}=4.81$ to 6.56). Incidence of brain abscess following AS was 0.11 per 10000 AS episodes $(95 \% \mathrm{Cl}=0.05$ to 0.26$)$. Incidence of orbital cellulitis following AS was 1.50 per 10000 AS episodes (95\% $\mathrm{Cl}=1.17$ to 1.90 ) (Table 3).

Incidence of acute mastoiditis following AOM in those aged $\leq 20$ years was 3.74 per $10000 \mathrm{AOM}$ consultations $(95 \% \mathrm{Cl}=3.01$ to 4.65), and 11.41 per 10000 AOM episodes $195 \% \mathrm{Cl}=9.17$ to 14.19$)$ in those aged $>20$ years. All episodes of brain abscess following AS occurred in those aged $>20$ years lincidence 0.12 per 10000 AS episodes; $95 \% \mathrm{Cl}=0.11$ to 0.13 ). Incidence of orbital cellulitis following AS in those aged $\leq 20$ years was 4.94 per 10000 AS episodes $(95 \% \mathrm{Cl}=2.89$ to 8.46$)$, and 1.28 per 10000 AS episodes $(95 \% \mathrm{Cl}=1.17$ to 1.39 ) in those aged $>20$ years (Table 4).

\section{Association between antibiotic prescription and outcomes}

The incidence of septic complications for those patients who were and were not prescribed antibiotics at initial consultation, and the associated OR and NNT, are shown in Table 3. The models that best fit the data for the association between antibiotic prescription and acute mastoiditis following AOM, and for orbital cellulitis and brain abscess following AS, only included age as a confounding variable. There was only one episode of brain abscess following $A O M$; therefore, it was not possible to assess the association with antibiotic prescription.

Antibiotic prescription at initial consultation was protective against development of acute mastoiditis following AOM (OR $0.54 ; 95 \% \mathrm{Cl}=0.37$ to 0.79 ) and 
Figure 2. CONSORT flow diagram for acute sinusitis (AS). CONSORT = Consolidated Standards of Reporting Trials. CPRD = Clinical Practice Research Datalink

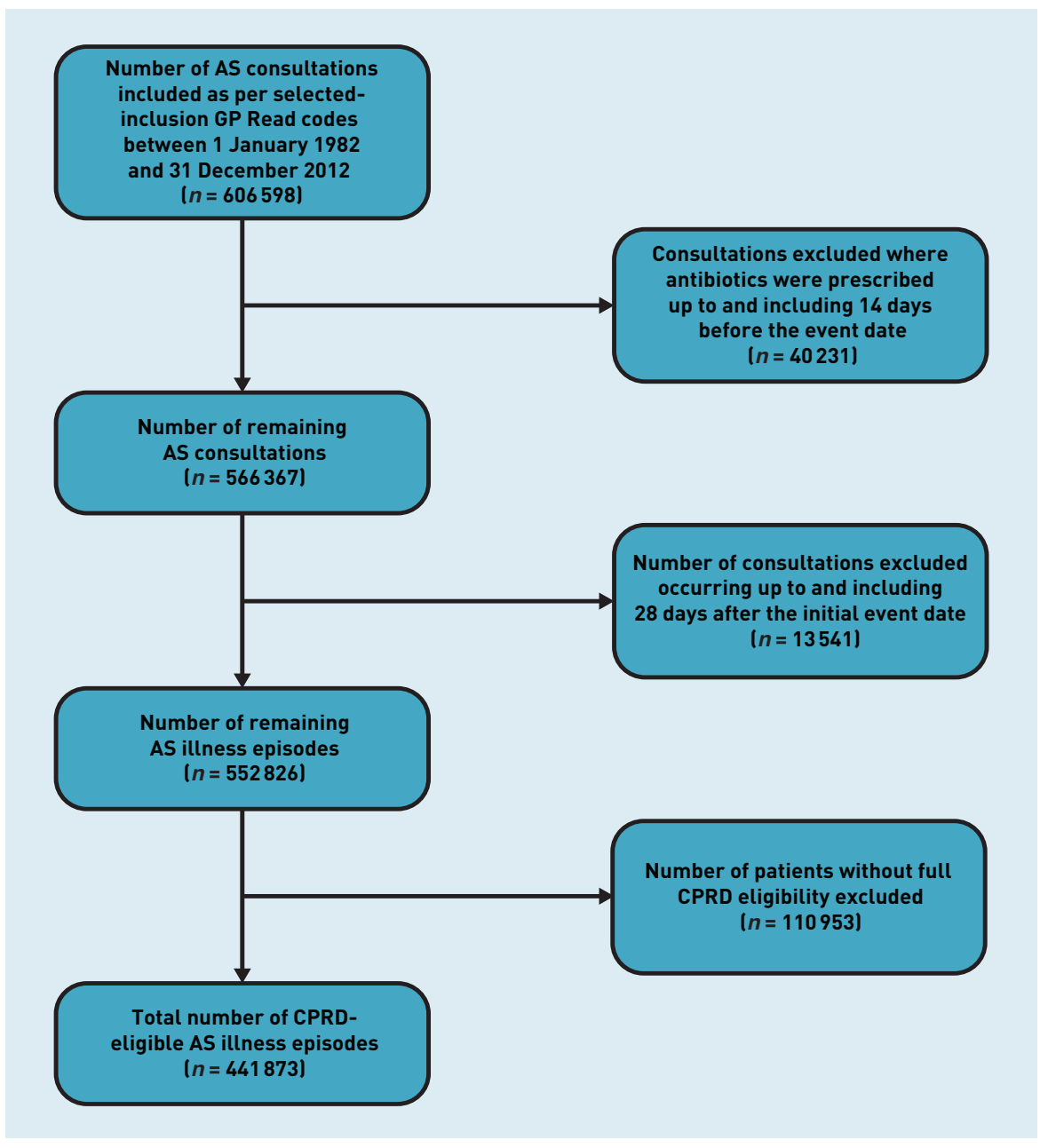

brain abscess following AS IOR 0.12; $95 \% \mathrm{Cl}=0.02$ to 0.70) (Table 3). However, as these are rare complications, the NNT to prevent one case was $2181(95 \% \mathrm{Cl}=1196$ to 5709) for acute mastoiditis following AOM and $19988(95 \% \mathrm{Cl}=4951$ to 167099$)$ for brain abscess following AS. No statistically significant association was identified between antibiotic prescription and development of orbital cellulitis following AS; however, the point estimate was in the direction of reduced odds.

\section{Stratified analyses}

The association between antibiotic prescription and septic complications stratified by age are shown in Table 4. Antibiotics showed a stronger protective benefit against development of acute mastoiditis following $\mathrm{AOM}$ in those aged $\leq 20$ years than in the whole cohort; however, no statistically significant association was seen in those aged $>20$ years.

All cases of brain abscess following AS occurred in those aged $>20$ years, and a statistically significant association was seen between antibiotic prescription and odds of developing brain abscess following AS in this age group (Table 4).

In those aged $\leq 20$ years a statistically significant association was demonstrated between antibiotic prescription and development of orbital cellulitis following AS (Table 4); however, as it is rare, the NNT to prevent one such case was 691 (95\% $\mathrm{Cl}=260$ to 2695 ).

\section{DISCUSSION}

\section{Summary}

These findings confirm that the incidence of serious complications following AOM and AS is very low, with only one out of 300000 patients with AOM developing a brain abscess, up to an incidence of 5.62 per 10000 episodes for acute mastoiditis following AOM. Evidence was found that antibiotic prescription is associated with reduced odds of acute mastoiditis following $\mathrm{AOM}$ and brain abscess following AS, with NNT of 2181 and 19 988, respectively. A non-significant association was found between antibiotic prescription and orbital 
Table 1. Baseline characteristics of the acute otitis media cohort

\begin{tabular}{|c|c|c|c|}
\hline Characteristic, $n(\%)$ & $\begin{array}{l}\text { Whole sample, } \\
\qquad N=286574\end{array}$ & $\begin{array}{l}\text { Prescribed antibiotics, } \\
N=249086(86.9 \%)\end{array}$ & $\begin{array}{l}\text { Not prescribed antibiotics, } \\
\qquad N=37488 \text { (13.1\%) }\end{array}$ \\
\hline \multicolumn{4}{|l|}{ Sex } \\
\hline Male & 140787 (49.1) & $122352(49.1)$ & 18435 (49.2) \\
\hline Female & 145787 (50.9) & $126734(50.9)$ & 19053 (50.8) \\
\hline \multicolumn{4}{|l|}{ Age, years } \\
\hline Medianª & 6 & 6 & 6 \\
\hline Interquartile range & $3-20$ & $3-19$ & $3-23$ \\
\hline \multicolumn{4}{|l|}{ Age, years } \\
\hline $0-2$ & 55999 (19.5) & 49262 (19.8) & $6737(18.0)$ \\
\hline $3-5$ & 72164 (25.2) & 62704 (25.2) & 9460 (25.2) \\
\hline $6-10$ & 55968 (19.5) & $48226(19.4)$ & $7742(20.7)$ \\
\hline $11-20$ & 32318 (11.3) & 28577 (11.5) & $3741(10.0)$ \\
\hline $21-30$ & $16050(5.6)$ & $13984(5.6)$ & 2066 (5.5) \\
\hline $31-40$ & $18510(6.5)$ & $16029(6.4)$ & $2481(6.6)$ \\
\hline $41-50$ & $14040(4.9)$ & $12095(4.9)$ & 1945 (5.2) \\
\hline $51-60$ & $10427(3.6)$ & $8954(3.6)$ & $1473(3.9)$ \\
\hline $61-70$ & $6527(2.3)$ & $5543(2.2)$ & $984(2.6)$ \\
\hline 71-80 & 3334 (1.2) & $2731(1.1)$ & $603(1.6)$ \\
\hline$\geq 81$ & $1237(0.4)$ & 981 (0.4) & $256(0.7)$ \\
\hline Asplenic & $47(0.02)$ & $45(0.02)$ & $2(0.005)$ \\
\hline Chronic kidney disease & $95(0.03)$ & $81(0.03)$ & $14(0.04)$ \\
\hline CSF shunt & $61(0.02)$ & $49(0.02)$ & $12(0.03)$ \\
\hline HIV & $15(0.005)$ & $14(0.006)$ & $1(0.003)$ \\
\hline Immunocompromised & $151(0.05)$ & $137(0.06)$ & $14(0.04)$ \\
\hline Smoker & $14990(5.2)$ & 12948 (5.2) & $2042(5.4)$ \\
\hline Transplanted organ & $89(0.03)$ & $78(0.03)$ & $11(0.03)$ \\
\hline Diabetes mellitus & 3485 (1.2) & 2980 (1.2) & 505 (1.3) \\
\hline
\end{tabular}

aMedian was used to describe summary of age as data were skewed to the left. CSF = cerebrospinal fluid.

cellulitis following AS. In stratified analyses, antibiotic prescribing was only associated with a reduced odds of acute mastoiditis following AOM, and orbital cellulitis following $A S$, in those aged $\leq 20$ years. Cases of brain abscess following AS only occurred in those aged $>20$ years, and antibiotic prescription was found to significantly reduce the likelihood of this outcome in this age group.

\section{Strengths and limitations}

This was a large study investigating the development of serious complications following common RTIs. Use of the CPRD database facilitated inclusion of a large number of patients from a range of UK general practices, providing a highly representative sample. The CPRD is a widely used and well-validated database. . $^{1922}$ The cohort design enabled estimation of the incidence of serious complications following episodes of $\mathrm{AOM}$ and $\mathrm{AS}$; the effect of antibiotic prescription on the risk of such complications; and the number of patients that need to be treated with antibiotics in order to prevent a single instance of one such complication.
The use of routine data meant that the authors had to rely on the presence and accuracy of Read codes assigned by GPs to identify patients with $\mathrm{AOM}$ and $\mathrm{AS}$, as opposed to the use of strictly defined case definitions. Up to one-third of antibiotic prescriptions have been shown to have no associated diagnosis or symptom Read code: ${ }^{25}$ therefore, a number of patients with AOM or AS may not have been coded at all and will have been missed from this study. However, while coding of RTIs in primary care records is not sensitive, it is likely to be specific, and variability in coding may be related to GP rather than patient characteristics. Therefore, the incidence of consultations for these RTIs is likely to be underestimated from these data. It is nonetheless unlikely that acute mastoiditis, orbital cellulitis, and brain abscess have been misclassified, as such serious diagnoses would usually be made following extensive investigation in secondary care and are usually well-coded in HES and/or GP data. Therefore, the authors believe that the estimates of the incidence of serious complications following $\mathrm{AOM}$ or $\mathrm{AS}$, and the changes in risk associated with antibiotic 
Table 2. Baseline characteristics of the acute sinusitis cohort

\begin{tabular}{|c|c|c|c|}
\hline Characteristic, $n(\%)$ & $\begin{array}{l}\text { Whole sample } \\
\qquad=441873\end{array}$ & $\begin{array}{l}\text { Prescribed antibiotics } \\
\qquad N=407030(92.1 \%)\end{array}$ & $\begin{array}{l}\text { Not prescribed antibiotics } \\
\qquad N=34843(7.9 \%)\end{array}$ \\
\hline \multicolumn{4}{|l|}{ Sex } \\
\hline Male & 124781 (28.2) & 113934 (28.0) & $10847(31.1)$ \\
\hline Female & 317091 (71.8) & 293096 (72.0) & 23995 (68.9) \\
\hline Unknown & 1 (0.0002) & $0(0)$ & $1(0.002)$ \\
\hline \multicolumn{4}{|l|}{ Age, years } \\
\hline Mean & 45.6 & 45.8 & 43.8 \\
\hline SD & 16.4 & 16.4 & 16.4 \\
\hline \multicolumn{4}{|l|}{ Age, years, $n(\%)$} \\
\hline $0-2$ & $342(0.1)$ & $314(0.1)$ & $28(0.1)$ \\
\hline $3-5$ & $832(0.2)$ & 732 (0.2) & $100(0.3)$ \\
\hline $6-10$ & $2835(0.6)$ & $2479(0.6)$ & 356 (1.0) \\
\hline $11-20$ & 22281 (5.0) & $19968(4.9)$ & $2313(6.6)$ \\
\hline $21-30$ & 53078 (12.0) & 47976 (11.8) & $5102(14.6)$ \\
\hline $31-40$ & 99511 (22.5) & 91277 (22.4) & 8234 (23.6) \\
\hline $41-50$ & 95828 (21.7) & 89020 (21.9) & 6808 (19.5) \\
\hline $51-60$ & 81055 (18.3) & 75465 (18.5) & $5590(16.0)$ \\
\hline $61-70$ & 54158 (12.3) & $50442(12.4)$ & 3716 (10.7) \\
\hline $71-80$ & $24418(5.5)$ & 22549 (5.5) & $1869(5.4)$ \\
\hline$\geq 81$ & 7535 (1.7) & 6808 (1.7) & 727 (2.1) \\
\hline Asplenic & $285(0.1)$ & $266(0.1)$ & $19(0.1)$ \\
\hline Chronic kidney disease & $472(0.1)$ & $437(0.1)$ & $35(0.1)$ \\
\hline CSF shunt & $102(0.02)$ & $94(0.02)$ & $8(0.02)$ \\
\hline HIV & 73 (0.02) & $67(0.02)$ & $6(0.02)$ \\
\hline Immunocompromised & $681(0.2)$ & $631(0.2)$ & $50(0.1)$ \\
\hline Smoker & 82188 (18.6) & 76006 (18.7) & $6182(17.7)$ \\
\hline Transplanted organ & $326(0.1)$ & $301(0.1)$ & $25(0.1)$ \\
\hline Diabetes mellitus & $19477(4.4)$ & $18077(4.4)$ & $1400(4.0)$ \\
\hline
\end{tabular}

prescribing, are likely to be valid. Routine primary care data only provide information on antibiotic prescribing and not antibiotic consumption; therefore, these estimates reflect the association between being prescribed an antibiotic and developing a complication, as opposed to taking an antibiotic and developing a complication.
This study was also unable to identify the use of delayed antibiotic prescriptions, but there is no evidence that delayed prescribing was commonly used before 2012

This study is at risk of indication/ selection bias, in that individuals with a more severe illness are more likely to have been prescribed antibiotics, and more likely

\section{Table 3. Association between antibiotic prescription and complications}

\begin{tabular}{|c|c|c|c|c|c|c|c|c|c|}
\hline \multirow[b]{2}{*}{ Complication } & \multicolumn{3}{|c|}{ Complications, $n$} & \multicolumn{3}{|c|}{ Incidence $(95 \% \mathrm{Cl})$} & \multicolumn{3}{|c|}{ OR $(95 \%$ Cl $)$} \\
\hline & Total & Antibiotics & No antibiotics & Overall incidence & Antibiotics & No antibiotics & Crude & Adjusted $^{b}$ & NNT \\
\hline $\begin{array}{l}\text { Brain abscess } \\
\text { following } A O M\end{array}$ & 1 & 1 & 0 & 0.03 (0.01 to 0.20 ) & $\begin{array}{c}0.04 \\
(0.03 \text { to } 0.05)\end{array}$ & $\mathrm{N} / \mathrm{A}$ & N/A & N/A & N/A \\
\hline $\begin{array}{l}\text { Acute mastoiditis } \\
\text { following AOM }\end{array}$ & 161 & 125 & 36 & 5.62 (4.81 to 6.56$)$ & $\begin{array}{c}5.02 \\
\text { (4.21 to } 5.98)\end{array}$ & $\begin{array}{c}9.60 \\
\text { (6.94 to } 13.29)\end{array}$ & $\begin{array}{c}0.52 \\
(0.36 \text { to } 0.76)\end{array}$ & $\begin{array}{c}0.54 \\
\text { (0.37 to } 0.79 \text { ) }\end{array}$ & $\begin{array}{c}2181 \\
\text { (1196 to } 5709 \text { ) }\end{array}$ \\
\hline $\begin{array}{l}\text { Brain abscess } \\
\text { following AS }\end{array}$ & 5 & 3 & 2 & 0.11 (0.05 to 0.26$)$ & $\begin{array}{c}0.07 \\
(0.03 \text { to } 0.22)\end{array}$ & $\begin{array}{c}0.57 \\
(0.16 \text { to } 2.10)\end{array}$ & $\begin{array}{c}0.13 \\
(0.02 \text { to } 0.77)\end{array}$ & $\begin{array}{c}0.12 \\
(0.02 \text { to } 0.70)\end{array}$ & $\begin{array}{c}19988 \\
\text { (4951 to } 167099 \text { ) }\end{array}$ \\
\hline $\begin{array}{l}\text { Orbital cellulitis } \\
\text { following AS }\end{array}$ & 66 & 57 & 9 & 1.50 (1.17 to 1.90$)$ & $\begin{array}{c}1.40 \\
(1.08 \text { to } 1.81)\end{array}$ & $\begin{array}{c}2.58 \\
(1.36 \text { to } 4.91)\end{array}$ & $\begin{array}{c}0.54 \\
(0.27 \text { to } 1.10)\end{array}$ & $\begin{array}{c}0.56 \\
(0.27 \text { to } 1.12)\end{array}$ & N/A \\
\hline
\end{tabular}

${ }^{a}$ Per $10000 \mathrm{AOM} / \mathrm{AS}$ primary care consultations. ${ }^{b} \mathrm{Adjusted}$ for patient's age at the time of consultation. $\mathrm{AOM}=$ acute otitis media. AS = acute sinusitis. $\mathrm{Cl}=$ confidence interval. N/A = not applicable. NNT = numbers needed to treat. OR=odds ratio. 
Table 4. Association between antibiotic prescription and complications in those aged $\leq 20$ years and
$>20$ years

\begin{tabular}{|c|c|c|c|c|c|c|c|c|}
\hline \multicolumn{9}{|c|}{ Patients aged $\leq 20$ years } \\
\hline \multirow[b]{2}{*}{ Complication } & \multicolumn{3}{|c|}{ Complications, $n$} & \multicolumn{3}{|c|}{ Incidence $(95 \% \mathrm{Cl})$} & \multirow[b]{2}{*}{ OR $(95 \% \mathrm{Cl})$} & \multirow[b]{2}{*}{ NNT $(95 \% \mathrm{Cl})$} \\
\hline & Total & On antibiotics & No antibiotics & Overall incidence & On antibiotics & No antibiotics & & \\
\hline $\begin{array}{l}\text { Acute mastoiditis } \\
\text { following AOM }\end{array}$ & 81 & 61 & 20 & $\begin{array}{c}3.74 \\
\text { (3.01 to } 4.65 \text { ) }\end{array}$ & $\begin{array}{c}3.23 \\
\text { (2.52 to } 4.15)\end{array}$ & $\begin{array}{c}7.23 \\
\text { (4.68 to } 11.16 \text { ) }\end{array}$ & 0.45 (0.27 to 0.74 ) & $\begin{array}{c}2504 \\
(1251-7776)\end{array}$ \\
\hline $\begin{array}{l}\text { Brain abscess } \\
\text { following AS }\end{array}$ & 0 & N/A & N/A & N/A & N/A & N/A & N/A & N/A \\
\hline $\begin{array}{l}\text { Orbital cellulitis } \\
\text { following AS }\end{array}$ & 13 & 8 & 5 & $\begin{array}{c}4.94 \\
\text { (2.89 to } 8.46 \text { ) }\end{array}$ & $\begin{array}{c}3.41 \\
\text { (1.73 to } 6.72)\end{array}$ & $\begin{array}{c}17.88 \\
\text { (7.64 to } 41.78 \text { ) }\end{array}$ & 0.19 (0.06 to 0.58 ) & $691(260-2695)$ \\
\hline
\end{tabular}

Patients aged $>20$ years

\begin{tabular}{|c|c|c|c|c|c|c|c|c|}
\hline \multirow[b]{2}{*}{ Complication } & \multicolumn{3}{|c|}{ Number of complications } & \multicolumn{3}{|c|}{ Incidence $\left.{ }^{(95 \%} \mathrm{Cl}\right)$} & \multirow[b]{2}{*}{ OR $(95 \% \mathrm{Cl})$} & \multirow[b]{2}{*}{ NNT $(95 \% \mathrm{Cl})$} \\
\hline & Total & On antibiotics & No antibiotics & Overall incidence & On antibiotics & No antibiotics & & \\
\hline $\begin{array}{l}\text { Acute mastoiditis } \\
\text { following AOM }\end{array}$ & 80 & 64 & 16 & $\begin{array}{c}11.41 \\
\text { (9.17 to } 14.19 \text { ) }\end{array}$ & $\begin{array}{c}10.61 \\
\text { (8.31 to } 13.55 \text { ) }\end{array}$ & $\begin{array}{c}16.31 \\
\text { (10.04 to } 26.48)\end{array}$ & 0.65 (0.37 to 1.13$)$ & N/A \\
\hline $\begin{array}{l}\text { Brain abscess } \\
\text { following AS }\end{array}$ & 5 & 3 & 2 & $\begin{array}{c}0.12 \\
(0.11 \text { to } 0.13)\end{array}$ & $\begin{array}{c}0.08 \\
(0.07 \text { to } 0.09)\end{array}$ & $\begin{array}{c}0.62 \\
(0.54 \text { to } 0.72)\end{array}$ & 0.13 (0.02 to 0.75 ) & $\begin{array}{c}18319 \\
(4549-146666)\end{array}$ \\
\hline $\begin{array}{l}\text { Orbital cellulitis } \\
\text { following AS }\end{array}$ & 53 & 49 & 4 & $\begin{array}{c}1.28 \\
(1.17 \text { to } 1.39)\end{array}$ & $\begin{array}{c}1.28 \\
(1.17 \text { to } 1.40)\end{array}$ & $\begin{array}{c}1.25 \\
\text { (1.13 to } 1.38)\end{array}$ & 1.02 (0.37 to 2.84 ) & N/A \\
\hline
\end{tabular}

a Per 10000 AOM/AS primary care consultations. AOM = acute otitis media. AS = acute sinusitis. $C l=$ confidence interval. N/A = not applicable. NNT= numbers needed to treat. OR = odds ratio.

to develop complications. As such, the identified beneficial effects of antibiotics may have been diluted and the associated NNTs overestimated.

Although a number of potential confounding factors were assessed for their association between antibiotic prescription and the outcomes, and the results adjusted for the effect of age, it is a possibility that unmeasured confounding may have biased the reported associations.

\section{Comparison with existing literature}

Several previous studies have examined the risk of serious complications following common RTIs, and attempted to assess whether antibiotics confer a protective effect. Two previous studies have used CPRD data to explore the risk of mastoiditis following AOM, but neither looked at the risk of brain abscess following AOM or AS, or orbital cellulitis following AS. ${ }^{18,19}$ Petersen et al ${ }^{18}$ did not report an incidence of mastoiditis following AOM, and Thompson et al ${ }^{19}$ only assessed the risk in children, reporting an incidence of mastoiditis within 3 months of otitis media of 2.4 per 10000 otitis media episodes. The incidence calculated by Thompson et a $l^{19}$ is lower than the 5.62 per 10000 identified in the present study, but the findings in the present study may be more representative of the actual incidence as the inclusion criteria was more specific and only included codes for AOM. Both of these previous studies also explored the protective effect of prescribing antibiotics for AOM on the risk of mastoiditis, and reported ORs remarkably similar to the present study (Petersen et al OR 0.56; $95 \% \mathrm{Cl}=0.37$ to 0.86); (Thompson et al OR $0.56 ; 95 \% \mathrm{Cl}=0.44$ to 0.71 ); (present study OR $0.54 ; 95 \% \mathrm{Cl}=0.37$ to 0.79 ). ${ }^{18,19}$ However, these results demonstrated a larger absolute difference and therefore smaller NNT to prevent a single instance of one complication (Peterson et al NNT = 4064; Thompson et al NNT = 4831; present study NNT $=2181) .{ }^{18,19}$ Again, this is likely due to the increased specificity of the diagnostic codes for AOM used in the present study.

A Swedish study ${ }^{20}$ used both an ecological time-trend analysis and a prospective cohort to explore the risk of serious complications following RTIs, and the association with antibiotic prescribing. They calculated a lower risk of orbital abscess following sinusitis than the present study 0.16 per 10000 consultations for those not prescribed antibiotics; 0.05 per 10000 consultations for those prescribed antibiotics), but a similar risk of brain abscess following sinusitis 10.16 per 10000 consultations for those not prescribed antibiotics; 0.10 per 10000 consultations 
for those prescribed antibiotics). ${ }^{20}$ However, the Swedish study did not calculate the relative risk of developing orbital abscess or brain abscess following sinusitis in those prescribed antibiotics compared with those not prescribed antibiotics. In their ecological study they found no association between antibiotic use and incidence of bacterial complications, such as mastoiditis and extradural/subdural abscess, despite a significant decrease in the volume of antibiotics dispensed between 2006 and 2015.

Gulliford et al explored practice-level associations between antibiotic prescribing for RTIs and incidence of pneumonia, peritonsillar abscess, mastoiditis, empyema, meningitis, intracranial abscess, and Lemierre's syndrome. They found associations between antibiotic prescribing and both pneumonia and peritonsillar abscess, but not for mastoiditis or brain abscess. ${ }^{26}$ They also conducted a cluster randomised controlled trial in UK general practice that resulted in a $12 \%$ reduction in antibiotic prescribing for RTIs in intervention practices, but found no evidence of an increase in serious bacterial complications such as mastoiditis and intracranial abscess in these practices. ${ }^{27}$

Finally, a US study ${ }^{28}$ of hospital admissions where both intracranial abscess and rhinosinusitis had been coded estimated an incidence of brain abscess following sinusitis of 2.7-4.4 per million child-years, and a systematic review of cases of brain abscess identified that 30\% had associated otitis media or mastoiditis. ${ }^{29}$ However, no other studies were found examining the association between antibiotic prescribing and brain abscess at the individual level.

\section{Funding}

No funding was received for this study.

\section{Ethical approval}

This study was approved by the Independent Scientific Advisory Committee for MHRA database research on 24 January 2014 (protocol ref: 13_202R).

\section{Provenance}

Freely submitted; externally peer reviewed.

\section{Competing interests}

The authors have declared no competing interests.

\section{Acknowledgements}

The authors would like to thank Chris Poole for supporting data extraction.

\section{Discuss this article}

Contribute and read comments about this article: bjgp.org/letters

\section{Implications for research and practice}

A key message emerging from the present study is that acute mastoiditis following $\mathrm{AOM}$ and orbital cellulitis following AS are rare events, and brain abscess is very rare following $A O M$ or $A S$. These findings suggest that not prescribing antibiotics for AOM and AS may be associated with very small increases in the risk of serious complications, but that very large numbers would need to be treated to prevent each complication. These findings also indicate that antibiotic protection is not complete, as even those who were prescribed antibiotics had a small risk of these complications. Therefore, given the current threat from antibiotic resistance, lack of symptomatic benefit from antibiotic use for these conditions, and risk of adverse effects from antibiotics, these results should not change current recommendations to not prescribe antibiotics for the majority of cases of AOM and AS. However, these findings highlight the importance of ensuring that consultations for $\mathrm{AOM}$ and AS include discussion around the natural history of the disease and routinely provide safety-netting advice. The present study did not assess whether any specific risk factors were associated with development of these serious complications; therefore, future research focusing on predisposing conditions/clinical features that may increase the risk of such complications would add valuable evidence to current knowledge on this topic.

The present study's findings provide reassurance that serious complications of $\mathrm{AOM}$ and $\mathrm{AS}$ are rare. Although it was identified that prescription of antibiotics at initial consultation may reduce the risk of acute mastoiditis following $\mathrm{AOM}$ and brain abscess following AS, large numbers of patients would need to be treated to prevent one complication, and even those prescribed antibiotics had a very small risk of such complications. Therefore, the authors do not advocate changing current recommendations to avoid prescription of antibiotics in the majority of cases of AOM and AS. 


\section{REFERENCES}

1. World Health Organization. The evolving threat of antimicrobial resistance. Options for action. 2012. http://whqlibdoc.who.int/ publications/2012/9789241503181_eng.pdf (accessed 20 Feb 2020).

2. O'Neill J. Tackling drug-resistant infections globally: final report and recommendations. The Review on Antimicrobial Resistance, 2016. https:// amr-review.org/sites/default/files/160525_Final\%20paper_with\%20cover.pdf laccessed 20 Feb 2020).

3. Public Health England. English surveillance programme for antimicrobial utilisation and resistance (ESPAUR). Report 2018. 2018. https://webarchive. nationalarchives.gov.uk/20191003132022/https://www.gov.uk/government/ publications/english-surveillance-programme-antimicrobial-utilisation-andresistance-espaur-report (accessed 20 Feb 2020).

4. NHS, National Institute for Health and Care Excellence. Respiratory tract infections - antibiotic prescribing. Prescribing of antibiotics for self-limiting respiratory tract infections in adults and children in primary care. CG69. London: NICE, 2008. https://www.nice.org.uk/guidance/cg69/evidence/fullguideline-pdf-196853293 (accessed 20 Feb 2020).

5. Gulliford MC, Dregan A, Moore MV, et al. Continued high rates of antibiotic prescribing to adults with respiratory tract infection: survey of $568 \mathrm{UK}$ general practices. BMJ Open 2014; 4(10): e006245.

6. Hawker JI, Smith S, Smith GE, et al. Trends in antibiotic prescribing in primary care for clinical syndromes subject to national recommendations to reduce antibiotic resistance, UK 1995-2011: analysis of a large database of primary care consultations. J Antimicrob Chemother 2014; 69(12): 3423-3430.

7. Pouwels KB, Dolk FCK, Smith DRM, et al. Actual versus 'ideal' antibiotic prescribing for common conditions in English primary care. J Antimicrob Chemother 2018; 73(Suppl 2): 19-26.

8. Yates PD, Anari S. Otitis media. In: Lalwani AK, ed. Current diagnosis and treatment in otolaryngology - head and neck surgery. 2nd edn. New York, NY: McGraw-Hill Companies, 2009: 655-665.

9. Lemiengre MB, van Driel ML, Merenstein D, et al. Antibiotics for clinically diagnosed acute rhinosinusitis in adults. Cochrane Database Syst Rev 2012; 10 CD006089. DOI: 10.1002/14651858.CD006089.pub4

10. Betz CS, Issing W, Matschke J, et al. Complications of acute frontal sinusitis: a retrospective study. Eur Arch Otorhinolaryngol 2008; 265(1): 63-72.

11. Shah AR, Salamone FN, Tami TA. Acute and chronic sinusitis. In: Lalwani AK, ed. Current diagnosis and treatment in otolaryngology - head and neck surgery. 2nd edn. New York, NY: McGraw-Hill Companies, 2008: 273-281.

12. van Buchem FL, Knottnerus JA, Schrijnemaekers VJ, Peeters MF. Primarycare-based randomised placebo-controlled trial of antibiotic treatment in acute maxillary sinusitis. Lancet 1997; 349(9053): 683-687.

13. Venekamp RP, Sanders SL, Glasziou PP, et al. Antibiotics for acute otitis media in children. Cochrane Database Syst Rev 2015; 6: CD000219. DOI: 10.1002/14651858.CD000219.pub3.
14. Young J, De Sutter A, Merenstein D, et al. Antibiotics for adults with clinically diagnosed acute rhinosinusitis: a meta-analysis of individual patient data. Lancet 2008; 371(9616): 908-914.

15. National Institute for Health and Care Excellence, Public Health England. Sinusitis (acute): antimicrobial prescribing. NG79. London: NICE, 2017. https:// www.nice.org.uk/guidance/ng79/resources/sinusitis-acute-antimicrobialprescribing-pdf-1837642625989 (accessed 20 Feb 2020).

16. National Institute for Health and Care Excellence, Public Health England. Otitis media (acute): antimicrobial prescribing. NG91. London: NICE, 2018. https:// www.nice.org.uk/guidance/ng91/resources/otitis-media-acute-antimicrobialprescribing-pdf-1837750121413 (accessed 20 Feb 2020).

17. Xiao F, Tseng MY, Teng LJ, et al. Brain abscess: clinical experience and analysis of prognostic factors. Surg Neurol 2005; 63(5): 442-450.

18. Petersen I, Johnson AM, Islam A, et al. Protective effect of antibiotics against serious complications of common respiratory tract infections: retrospective cohort study with the UK General Practice Research Database. BMJ 2007; 335(7627): 982

19. Thompson PL, Gilbert RE, Long PF, et al. Effect of antibiotics for otitis media on mastoiditis in children: a retrospective cohort study using the United Kingdom General Practice Research Database. Pediatrics 2009; 123(2): 424-430.

20. Cars T, Eriksson I, Granath A, et al. Antibiotic use and bacterial complications following upper respiratory tract infections: a population-based study. BMJ Open 2017; 7(11): e016221

21. Gonzalez-Gonzalez C, López-Vázquez P, Vázquez-Lago JM, et al. Effect on physicians' attitudes and knowledge on the quality of antibiotic prescription: a cohort study. PLoS One 2015; 10(10): e0141820.

22. Herrett E, Thomas SL, Schoonen WM, et al. Validation and validity of diagnoses in the General Practice Research Database: a systematic review. Br J Clin Pharmacol 2009; 69(1): 4-14

23. Joint Formulary Committee. British National Formulary 64. London: Pharmaceutical Press, 2012.

24. Wilson EB. Probable inference, the law of succession, and statistical inference. J Am Stat Assoc 1927; 22(158): 209-212.

25. Dolk FCK, Pouwels KB, Smith DRM, et al. Antibiotics in primary care in England: which antibiotics are prescribed and for which conditions? J Antimicrob Chemother 2018; 73(Suppl 2): ii2-ii10.

26. Gulliford MC, Moore MV, Little P, et al. Safety of reduced antibiotic prescribing for self limiting respiratory tract infections in primary care: cohort study using electronic health records. BMJ 2016; 354: i3410.

27. Gulliford MC. Prevost AT, Charlton J, et al. Effectiveness and safety of electronically delivered prescribing feedback and decision support on antibiotic use for respiratory illness in primary care: REDUCE cluster randomised trial. BMJ 2019; 364: 1236

28. Piatt JH Jr. Intracranial suppuration complicating sinusitis among children: an epidemiological and clinical study. J Neurosurg Pediatr 2011; 7(6): 567-574.

29. Brouwer MC, Coutinho JM, van de Beek D. Clinical characteristics and outcome of brain abscess. systematic review and meta-analysis. Neurology 2014; 82(9): 806-813. 